\title{
Utilização de Recursos Educacionais Digitais (RED) em Aulas de Língua Portuguesa nos Anos Finais do Ensino Fundamental: Contribuições e Desafios
}

\author{
Rayssa Araújo Hitzschky1, Juliana Silva Arruda1, Cintia Arruda Lima1, Liliane \\ Maria Ramalho de Castro Siqueira1, José Aires de Castro Filho \\ 1 Universidade Federal do Ceará - UFC. \\ 2 Instituto Universidade Virtual - UFC Virtual. \\ \{hitzschkyrayssa, julianarruda24, arrucintia, lilianeramalho1609\}@gmail.c \\ om, airesdvirtual.ufc.br
}

\begin{abstract}
This study aims to investigate the use of RED of Portuguese Language, selected after a course of teacher training, in classes undertaken in the final years of Elementary School. For this, the following research actions were carried out: 1) Offering a teacher training; 2) Selection of RED of Portuguese Language available in a digital educational repository; 3) Planning and conducting classes with the selected NETs. It was verified the importance of the formative moment offered for the strengthening of the pedagogical mediation during the use of the RED, as well as of the previous planning and pedagogical intentionality. In addition to the use of resources, students were able to take advantage of the multifaceted nature of ICT, strengthening student autonomy.
\end{abstract}

Resumo. Este estudo busca investigar a utilização de RED de Língua Portuguesa, selecionados após um curso de formação docente, em aulas empreendidas nos anos finais do Ensino Fundamental. Para isso, foram realizadas as seguintes ações de pesquisa: 1) Oferta de uma formação de professores; 2) Seleção de RED de Língua Portuguesa disponiveis em um repositório educacional digital; 3) Planejamento e realização de aulas com os RED selecionados. Verificou-se a importância do momento formativo oferecido para o fortalecimento da mediação pedagógica durante o uso dos RED, bem como do planejamento prévio e da intencionalidade pedagógica. Para além da utilização dos recursos, os alunos puderam aproveitar o caráter multifacetário das TIC, fortalecendo a autonomia discente.

\section{Introdução}

A utilização de recursos digitais vem se tornando expressiva nos ambientes educacionais. Hoje, existe uma preocupação contemporânea em inserir as chamadas Tecnologias da Informação e Comunicação (TIC) nas práticas pedagógicas, para atender as demandas de comunicabilidade, conhecimento e formação profissional existentes. Porém, como aponta Valente (2014), esta inserção carece de aprofundamento, tendo em vista que as salas de aula ainda apresentam a mesma 
estrutura e utilizam os mesmos métodos da educação do século passado. Nesse sentido, documentos que norteiam a educação brasileira discutem e fomentam o uso das TIC nos processos de ensino e de aprendizagem. Os Parâmetros Curriculares Nacionais (PCN), por exemplo, tecem como um dos seus objetivos gerais para o Ensino Fundamental, "saber utilizar diferentes fontes de informação e recursos tecnológicos para adquirir e construir conhecimento" [Brasil, 1997, p. 69]. Mais recentemente, a Base Nacional Comum Curricular (BNCC) aprofundou as discussões sobre o uso das TIC em sala de aula, ampliando a visão trazida pelos PCN. Segundo a BNCC, não basta apenas que o aluno saiba utilizar as TIC, mas ele deve utilizá-las a partir de uma compreensão, utilização e criação crítica, significativa, reflexiva e ética nas práticas sociais, incluindo as escolares. Objetiva-se, com isso, que o aluno manipule as tecnologias digitais para uso próprio e coletivo, acessando e disseminando informações; produzindo conhecimentos, resolvendo problemas e exercendo protagonismo e autoria nos diferentes campos sociais [Brasil, 2017, p. 9]. Dentre as TIC com finalidades pedagógicas, têm-se os Recursos Educacionais Digitais (RED). Os RED, de forma geral, são qualificados como recursos digitais, incluindo softwares, aplicativos educacionais e Objetos de Aprendizagem (OA), constituídos a partir de suas ferramentas multimidiáticas, como textos, imagens, áudios, vídeos e animações [Medeiros et al. 2018]. Observa-se, por exemplo, que na área de Língua Portuguesa ocorre uma progressiva influência dos RED, nos quais os conteúdos escolares incluem as chamadas práticas sociais de referência, marcadas pela diversidade cultural, linguística e tecnológica [Caiado e Morais 2013; Catto 2013]. A BNCC reforça essa discussão, a partir das denominadas "práticas de linguagem contemporâneas" [Rojo e Moura 2012]. Desse modo, a utilização de RED mostra-se como uma alternativa relevante para que as TIC sejam inseridas em práticas educacionais, em especial, no estudo da Língua Portuguesa. Partindo dessa premissa, surge o questionamento: De que forma RED de Língua Portuguesa, selecionados após um curso de formação docente, podem ser utilizados em aulas transcorridas nos anos finais do Ensino Fundamental?

O presente estudo, oriundo de um projeto de extensão, tem como objetivo geral investigar a utilização de RED de Língua Portuguesa, selecionados após um curso de formação docente, em aulas empreendidas nos anos finais do Ensino Fundamental. Como objetivos específicos, apresenta-se: 1) Compreender as possíveis contribuições proporcionadas pela utilização de RED de Língua Portuguesa; 2) Identificar os desafios vivenciados durante a utilização de RED de Língua Portuguesa em aulas nos anos finais do Ensino Fundamental. A pesquisa, qualitativa e com caráter descritivo, busca aprofundar as discussões em torno da utilização de Recursos Educacionais Digitais em práticas pedagógicas, com ênfase na área de Língua Portuguesa. Além disso, busca-se estreitar o compartilhamento de experiências que fizeram uso de RED em contextos escolares, aliados à formação docente.

\section{Referencial Teórico}

\subsection{Recursos Educacionais Digitais e a área de Língua Portuguesa: reflexões para o ensino e para a aprendizagem}

As tecnologias digitais vêm sendo progressivamente utilizadas em práticas contemporâneas, seja para realizar a compra de algum produto, para a comunicação ou para a busca de informação e conhecimento. Os smartphones, tablets, laptops e desktops 
estão cada vez mais integrados às ações corriqueiras do dia a dia, mostrando que muito do real acontece no meio virtual e/ou digital. Os avanços encontrados, por exemplo, no campo da inteligência artificial, evidenciam a presença marcante das tecnologias digitais a curto e longo prazo. Ainda na Modernidade, um longo processo de inserção das TIC nas escolas foi consolidado. Em 1983, iniciou-se o Projeto EDUCOM, marco inicial para a disseminação das tecnologias digitais no ensino brasileiro [Loureiro e Lopes 2012]. Quase quarenta anos depois, as TIC evidenciam o seu poder, estando presentes em diversas instâncias sociais, dentre elas, as escolares. Percebe-se, assim, a promoção de diversos projetos com fins educacionais, como o Projeto Um Computador Por Aluno (UCA), que teve como objetivo a distribuição de laptops educacionais para cerca de 300 escolas de cinco municípios brasileiros, além do fornecimento de Internet e de capacitação para gestores e professores [Castro-Filho et al. 2015]. Dentre as diversas TIC disponíveis, observa-se a ampla produção e disponibilização dos intitulados Recursos Educacionais Digitais (RED) [Ramos et al. 2011]. Esses recursos, caracterizados por serem digitais e por possuírem a finalidade de auxiliar o ensino e a aprendizagem, estão sendo cada vez mais difundidos no meio digital. Exemplo disso é a Plataforma MEC de Recursos Educacionais Digitais, do Ministério da Educação (MEC), concebida em 2015. Esta plataforma tem como objetivo reunir e disponibilizar RED oriundos dos principais repositórios brasileiros, como Portal do Professor e Banco Internacional de Objetos Educacionais (BIOE), facilitando a busca e o acesso aos recursos. Os RED podem ser encontrados em diferentes tipos, dentre eles simulações, animações, hipertextos, hipermídias e inclusive, Objetos de Aprendizagem. Para Ramos et al. (2011), um recurso educativo digital, intitulado assim pelos autores, que possua elementos que permitem a simulação, a combinação multimídia e a interatividade, pode ajudar a desenvolver estratégias de ensino e de aprendizagem diversificados, levando à manipulação dos objetos, à interação com os elementos do recurso, à observação ou à representação dos fenômenos, ou ainda, à aprendizagem de conceitos e teorias por meio da combinação de imagens, palavras e sons. Nesse sentido, os RED, denominados dessa forma neste trabalho, podem oferecer possibilidades multimidiáticas aos docentes e aos alunos, com o desenvolvimento e a vivência de práticas educativas que diferem daquelas dos tradicionais meios de ensino, dinamizando a aprendizagem. A ideia não é desconsiderar os meios consagrados de ensino, como o lápis, o livro ou o quadro, mas sim de considerar a diversidade oferecida por meio dos RED, a partir de suas ferramentas digitais e, algumas vezes, on-line e colaborativas.

$\mathrm{Na}$ área de Língua Portuguesa, a discussão em torno da influência das TIC para a abordagem de conteúdos curriculares vem sendo fortalecida. A BNCC reforça a necessidade de utilização desses recursos, afirmando que uma de suas competências específicas é "mobilizar práticas da cultura digital, diferentes linguagens, mídias e ferramentas digitais para expandir as formas de produzir sentidos (nos processos de compreensão e produção), aprender e refletir sobre o mundo e realizar diferentes projetos autorais" [Brasil, 2017, p. 85]. O rol de ferramentas multimidiáticas oferecidas pelos RED envolve possibilidades de trabalho com as diversas linguagens contemporâneas, como as visuais, as sonoras, as icônicas, além das textuais. Quando se fala em inserir novos elementos à dinâmica de aprendizagem, percebe-se que "o desafio consiste em criar condições didáticas que contribuam efetivamente para transformar a diversidade em uma vantagem pedagógica" [Lerner, 2002, p. 6], permitindo articular o trabalho colaborativo e as individualidades dos alunos ao uso das TIC. Para Caiado e Morais (2013), as atividades de Língua Portuguesa com as tecnologias digitais tornam- 
se instigantes e significativas quando é possível visualizar, ouvir e sentir o que está sendo estudado, devido à multimodalidade propiciada pelas TIC. Assim, a inserção destes recursos no espaço escolar "permite desenhar uma nova configuração desse contexto e implementar novas formas de se relacionar com ele. A partir dele, os professores têm que, necessariamente, planejar novas práticas educativas e desenvolver novos tipos de interação com seus alunos" [Caiado e Morais, 2013, p. 583-584]. Os RED, portanto, podem influenciar positivamente os espaços educacionais, diversificando as práticas pedagógicas por meio de suas ferramentas multimidiáticas. A área de Língua Portuguesa, em especial, pode favorecer-se das TIC para o estudo das linguagens contemporâneas, aproximando o conhecimento prévio dos alunos vivenciado fora do ambiente escolar aos conteúdos curriculares formalmente estudados, a partir de planejamentos escolares que mesclem abordagens tradicionais de ensino aos elementos proporcionados pelos RED.

\subsection{Formação docente e a utilização de Recursos Educacionais Digitais}

A influência das tecnologias digitais no âmbito social impulsiona o desenvolvimento e o compartilhamento de RED para o ensino e para a aprendizagem. Segundo Amaral et al. (2011), as TIC têm favorecido consideravelmente a reformulação das estratégias de ensino, proporcionando diferentes ferramentas e artefatos para o apoio ao processo de aprendizagem. Em vista dessa atual conjuntura, faz-se necessária a promoção de cursos de formação envoltos de intencionalidades pedagógicas e experimentações práticas, buscando proporcionar aos professores autonomia e criticidade para a inserção de RED em suas práticas. Nesse sentido, durante a realização de formações, os docentes precisam ter acesso a conhecimentos sobre conceituação teórica dos RED, suas especificidades e possíveis aplicações na escola, trazendo, por exemplo, a importância das ferramentas que os compõem. Veiga e D'Ávila (2008) consideram que a formação docente deve ser continuada e aliada à profissão de ser professor, que é constituída pela práxis em sala de aula e pelas situações e relações em sociedade. A prática docente, portanto, deve ser pautada na reflexão, ou seja, o professor em sala de aula também aprende por meio da sua experiência prática, sendo esse conhecimento uma fonte de ações reflexivas. Por isso, a importância da formação continuada partir do próprio contexto de trabalho dos professores [Arruda et al. 2016]. Essa relevância reflete-se em uma ação de formação na qual os sujeitos participantes, os professores, tornam-se agentes ativos do processo de conhecimento, apropriando-se, como enfatiza Fernandes (2005), do pensar educacional, ultrapassando a visão de um mero receptor das políticas públicas. Dessa maneira, abrange-se um processo anterior de internalização e de reflexão estabelecido pelo próprio docente. Ainda nesse caminho, Hitzschky et al. (2016) enfatizam a necessidade de compreensão das TIC como um suporte educacional que pode proporcionar possibilidades de aprendizagem quando incorporadas às práticas pedagógicas. A partir dos estudos recentes que dissertam sobre a preocupação com a formação de professores e as TIC, surge a necessidade de se analisar como os docentes vêm inserindo e utilizando RED em suas práticas após processos formativos anteriores, o que demanda um caráter permanente de aprofundamento. A seguir, será apresentado o contexto da pesquisa, assim como a descrição dos instrumentos de coleta dos dados e os procedimentos de análise. 


\section{Metodologia}

O presente estudo, de abordagem qualitativa e com natureza descritiva, foi realizado no âmbito do Projeto Athena - Desenvolvimento e uso de um repositório virtual aberto: importância da catalogação de Recursos Educacionais Digitais (RED), pertencente ao Grupo de Pesquisa e Produção de Ambientes Interativos e Objetos de Aprendizagem (PROATIVA), da Universidade Federal do Ceará (UFC). O projeto teve como objetivo investigar a realização de quatro aulas que utilizaram RED de Língua Portuguesa, após a promoção de um curso de formação docente. A pesquisa é qualitativa, pois a fonte direta dos dados foi o ambiente natural, no qual os investigadores estiveram em contato contínuo com a situação onde os fenômenos emergiram [Bogdan e Biklen 1991]. Para estes autores, o estudo é descritivo, visto que a análise dos dados buscou descrever em detalhes o processo realizado. As aulas foram ministradas por quatro professores de Língua Portuguesa dos anos finais do Ensino Fundamental em uma escola pública de Fortaleza (CE). Anteriormente às aulas, uma equipe pedagógica e técnica ofereceu uma formação aos professores, com o objetivo de apropriar os docentes para a utilização de um repositório educacional digital, chamado Athena, e outros repositórios que possuem RED, para o uso em suas práticas pedagógicas. Ao final, os professores transporam os conhecimentos trabalhados ao longo dos momentos formativos e levaram-nos para as suas práticas exercidas em sala de aula. Vale ressaltar que, como foco deste trabalho, a investigação concentrou-se nos momentos finais do ciclo do projeto, no qual foram analisadas as quatro aulas especificamente. É oportuno destacar que o objetivo deste acompanhamento não foi o de avaliar as práticas educacionais exercidas pelos professores em sala de aula, mas sim o de verificar a utilização dos RED escolhidos e trabalhados pelos docentes em seus planejamentos pedagógicos. As aulas observadas foram realizadas em dias distintos, com turmas do $6^{\circ}$ ao $9^{\circ}$ ano, no turno da manhã e da tarde. A escolha da escola deu-se pela abertura da gestão para o curso de formação, além da existência de um Laboratório de Inovação Tecnológica equipado com chromebooks, fruto da parceria entre a UFC, a Prefeitura de Fortaleza e a Google. As aulas foram acompanhadas pelos formadores, a fim de auxiliar os professores nas aplicações. Os instrumentos utilizados para a coleta dos dados foram observação participante, diário de campo, registros fotográficos, bem como conversas informais com os alunos e com os professores. Ao final, aplicou-se um questionário on-line do Google Drive, para avaliação do curso de formação. Destaca-se que este formulário não será trabalhado nos resultados desta pesquisa, tendo em vista o objetivo desta investigação. Dessa forma, as ações da pesquisa (Figura 1) foram assim organizadas: 1) Oferta da formação; 2) Seleção dos RED oriundos do repositório educacional digital Athena; 3) Planejamento e realização das aulas com os RED escolhidos pelos professores. A formação buscou aproximar os docentes da temática em questão, entendendo que o trabalho com os RED requer uma apropriação prévia para o alcance de bons resultados. A seleção dos RED teve como objetivo a escolha do recurso que seria trabalhado pelo professor em sua aula, entendendo que a utilização das tecnologias digitais não se dá de forma isolada, mas acontece em conjunto com momentos formativos de estudo e de compartilhamento de experiências. O planejamento e a realização das aulas refletiram a transposição dos conhecimentos aprendidos para a prática in locus, com o uso dos RED. 


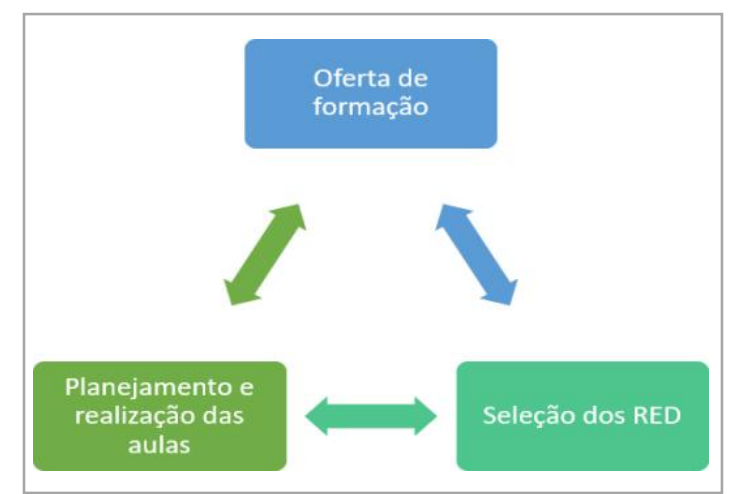

Figura 1. Ações da pesquisa

A metodologia foi traçada a partir da compreensão de que o uso de RED em práticas pedagógicas pode oferecer resultados satisfatórios quando aliados à formação docente e à apropriação destes recursos pelos docentes que os utilizarão em seus planejamentos. O uso de RED deve se sustentar no pressuposto de que as TIC não podem ser vistas como corpos estranhos, inseridos isoladamente na escola. Pelo contrário, elas devem ser integradas às práticas educacionais em sua compreensão global, contribuindo para o ecossistema escolar.

\section{Resultados e Discussões}

\subsection{Primeira aula: utilizando o RED Sinais de pontuação}

A primeira aula observada foi ministrada pela Professora A, intitulada assim neste excerto. Ela selecionou e utilizou o RED chamado Sinais de pontuação (Figura 2), presente no repositório Athena. O recurso trata-se de um vídeo e tem como objetivo apresentar os diferentes sinais de pontuação utilizados na Língua Portuguesa, assunto da aula. A aula foi iniciada com a retomada de um conteúdo já trabalhado, por meio de um vídeo em rima, um áudio e uma explicação em slides. Após esse momento, a professora solicitou que os alunos anotassem em seus cadernos o que estava sendo projetado no quadro. Durante a atividade, ela utilizou elementos de uma metodologia cooperativa, organizando os alunos em papéis previamente organizados: coordenador, relator, guardião do tempo e presidente. Os alunos mantiveram-se organizados em seus papéis, contudo, mostraram-se inquietos com o simples comando de cópia das informações vistas no quadro. Como forma de ganhar a atenção dos alunos, a professora iniciou o trabalho com o RED Sinais de pontuação. Nesse momento, alguns alunos reconheceram o vídeo apresentado, evidenciando que outros vídeos da série já haviam sido trabalhados em aulas anteriores. Os alunos mostraram-se atentos durante a apresentação do RED.
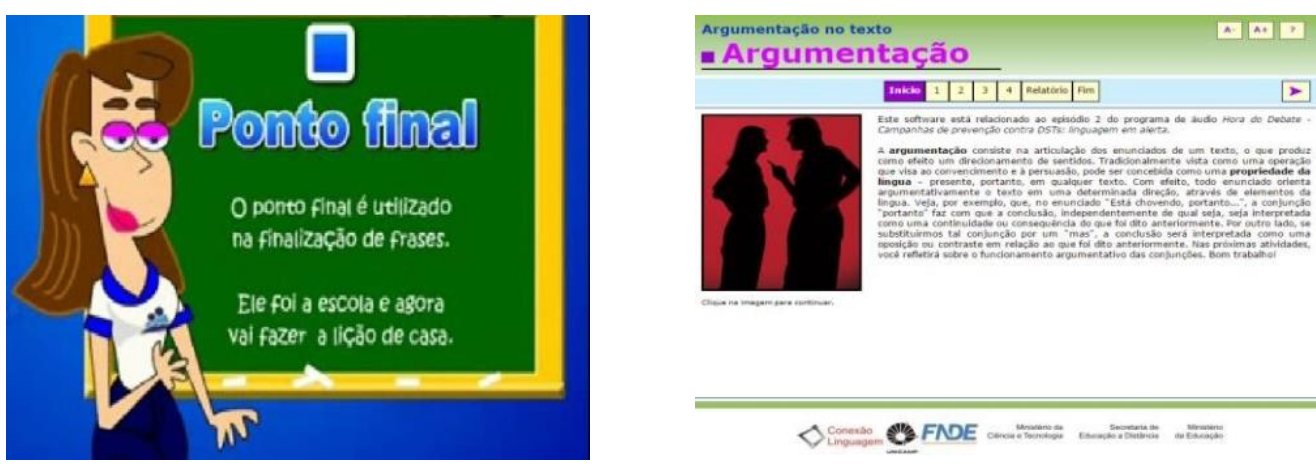
Figuras 2 e 3. Imagem do RED Sinais de pontuação; e Imagem do RED Argumentação no texto

Pode-se inferir que a Professora A utilizou diferentes recursos midiáticos, porém a aula foi estritamente expositiva, na qual os alunos não fizeram uso, em nenhum momento, dos chromebooks, mesmo tendo-os disponíveis. Além disso, a professora não desenvolveu com os alunos nenhuma atividade em sala como forma de aprofundar os conhecimentos apresentados em formato de slides ou por meio do RED trabalhado. Observou-se, então, que as tecnologias digitais, em geral, e o RED foram utilizados sem uma intencionalidade pedagógica clara.

\subsection{Segunda aula: utilizando o RED Argumentação no texto}

A segunda aula foi ministrada pela Professora B, que trabalhou o RED Argumentação no texto (Figura 3), também presente no repositório Athena. O objetivo da aula foi trabalhar as conjunções, e foi iniciada com o uso do Google Classroom, vinculado aos chromebooks disponíveis na escola. A professora, previamente, organizou o conteúdo e as atividades utilizadas na aula e os alunos, individualmente, tiveram acesso ao material. A professora teceu uma explanação sobre o conteúdo abordado, apontando as formas de utilização dos conectivos. Depois, pediu que dois alunos lessem o texto da atividade, resgatando exemplos do texto para explicar o uso das conjunções nas orações coordenadas e subordinadas, enquanto outro aluno foi convidado a ler um texto diferente. A professora explicou, mais uma vez, a presença das conjunções em algumas orações e, ao final, pediu que os alunos respondessem as questões da atividade. Para concluir a aula, a professora pediu que os alunos acessassem o repositório Athena e procurassem o RED Argumentação no texto. Por meio do recurso, os alunos puderam responder questões relativas às conjunções, trabalhando, novamente, com o conteúdo da aula. Apesar de conversas paralelas, a professora conseguiu a atenção de grande parte da turma, nos quais os alunos responderam rapidamente as atividades do RED. Percebeu-se que a professora conseguiu aplicar, de forma planejada e direcionada, os conhecimentos vistos na formação e encontrou no recurso escolhido, uma forma de revisão para o conteúdo explicado anteriormente. Além disso, ela aproveitou amplamente a estrutura disponível, organizando os alunos entre os chromebooks, e pensando a sua aula em torno de diferentes ferramentas digitais.

\subsection{Terceira aula: utilizando o RED Café com Língua Portuguesa: Morfossintaxe}

A terceira aula foi ministrada pela Professora $C$, que selecionou, dentre as opções do repositório Athena, o RED Café com Língua Portuguesa: Morfossintaxe (Figura 4). A aula teve como objetivo trabalhar o conteúdo regência verbal e foi iniciada com a explicação da professora sobre o tema. Em seguida, a professora pediu que os alunos acessassem o repositório e buscassem o RED. Os discentes não demonstraram dificuldade em encontrá-lo, no entanto, tiveram dificuldades quanto à resolução das atividades presentes no recurso. Observou-se que, diante das dificuldades, os alunos releram o texto explicativo presente no RED em vários momentos, apoiando-se no próprio recurso para elucidarem suas dúvidas. Percebeu-se, ainda, que frente às dificuldades enfrentadas pelos alunos, a professora não os instigou a compreender os enunciados em sua amplitude, mas, apenas, apontou as respostas nas orações, para que a atividade fosse concluída. Entende-se, portanto, que o trabalho com RED demanda o entendimento de que as tecnologias digitais não assumem o papel do professor na mediação pedagógica. Pelo contrário, a presença do docente torna-se ainda mais 
fundamental quando surgem dúvidas por parte dos alunos, pois é necessário que as hesitações sejam trabalhadas sem, necessariamente, apontar as respostas corretas, incluindo, assim, uma reflexão que deve ser feita pelos alunos.
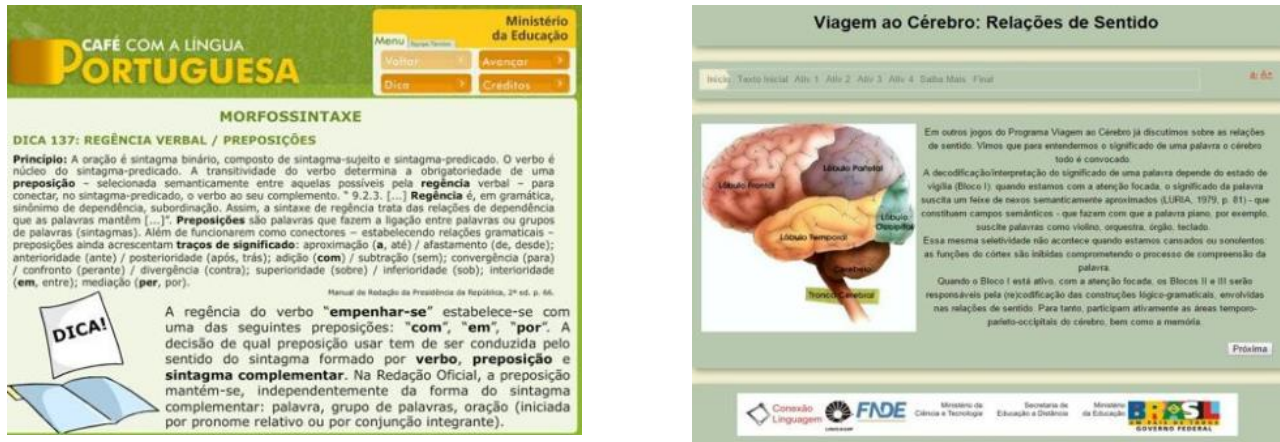

Figuras 4 e 5. Imagem do RED Café com Língua Portuguesa: Morfossintaxe; e Imagem do RED Viagem ao cérebro: relações de sentido

\subsection{Quarta aula: utilizando o RED Viagem ao cérebro: relações de sentido}

A quarta aula foi realizada pelo Professor D, que inicialmente, explanou sobre o conteúdo da aula, que foi interpretação textual, e depois ressaltou a importância da leitura atenta para a compreensão global de textos variados. Em seguida, os alunos foram orientados a acessarem o repositório Athena e a buscarem alguns RED que tratassem sobre o tema da aula, a partir das informações disponíveis. Observou-se que os alunos demonstraram dificuldades para abrir os recursos devido à lenta conexão. Aos poucos, os alunos conseguiram acessar o recurso Viagem ao cérebro: relações de sentido (Figura 5), indicado no planejamento pelo professor. Todos os alunos exploraram o recurso a partir das orientações do professor, realizando, primeiramente, a leitura do texto proposto no recurso e, depois, iniciando a resolução das atividades. Nesse momento, verificou- se que alguns estudantes aproveitaram para acessar outros sites, como por exemplo, o YouTube, mas, logo, voltaram a atenção para a atividade no recurso. Percebeu-se que os alunos estavam empolgados com o jogo de perguntas e respostas, ao mesmo tempo que comemoravam os acertos dos itens propostos. Como afirma Kapp (2012), a reestruturação dos processos de aprendizagem com o uso de elementos de gamificação são atividades que despertam interesse e motivam os jovens da atualidade e, portanto, são essenciais para o ambiente de sala de aula. Durante a leitura do texto presente no RED, observou-se que alguns alunos tiveram dificuldades em compreender o conceito de determinadas palavras. Buscando sanar suas dúvidas, eles abriram a ferramenta de busca do Google e procuraram o significado dos termos desejados, evidenciando autonomia ao buscar alternativas que pudessem auxiliá-los. Nesse caso, as TIC constituíram-se um instrumento de suporte para a autonomia demonstrada, já que os alunos tinham fácil acesso aos motores de busca proporcionados pela Internet. Ao final da atividade, o professor solicitou que os alunos pesquisassem mais recursos no repositório, explorando, assim, a curiosidade do grupo. O professor também pediu que os alunos falassem a respeito de suas impressões e opiniões sobre a aula, bem como sobre os recursos disponíveis no repositório. Os discentes afirmaram ter gostado da aula e falaram sobre o encantamento frente à diversidade de recursos existentes no repositório, mostrando que eles reconheceram os RED como aliados em seu processo de aprendizagem. A partir dessa aula, pode-se compreender que apesar dela ter sido planejada em torno de um recurso específico, a utilização das TIC não se resumiu apenas a uma seleção isolada. Os alunos aproveitaram o caráter multifacetário 
das tecnologias, utilizando-se de ferramentas de pesquisa e outros RED disponíveis em prol do desenvolvimento da aprendizagem.

\section{Considerações finais}

A partir das vivências dos professores, procurou-se investigar a utilização de RED com base em questões teóricas e práticas, objetivando responder à pergunta inicial da pesquisa: De que forma RED de Língua Portuguesa, selecionados após um curso de formação docente, podem ser utilizados em aulas transcorridas nos anos finais do Ensino Fundamental? As ações docentes com uso de RED promoveram interações e aplicações, por meio de atividades que possibilitaram uma abordagem mais multimidiática para os conteúdos propostos. Esse contexto levou ao alcance do objetivo geral de investigar a utilização de RED de Língua Portuguesa, selecionados após um curso de formação docente, em aulas empreendidas nos anos finais do Ensino Fundamental. $\mathrm{O}$ primeiro objetivo específico buscou compreender as possíveis contribuições proporcionadas pela utilização de RED de Língua Portuguesa em aulas realizadas nos anos finais do Ensino Fundamental. A partir dele, verificou-se o papel exercido pelos professores, demonstrando a sua função mediadora e crucial, a partir da seleção dos RED e da inserção dos recursos em seus planejamentos, perpassando a aplicabilidade prática em sala de aula. Durante esse percurso, constatou-se que os conhecimentos aprendidos e vivenciados durante a formação, aliados aos conhecimentos prévios dos professores, possibilitaram que as aulas se tornassem mais dinâmicas e ilustrativas, ao trazer diversas linguagens presentes nos RED, paralelamente às práticas subjetivas dos professores. Promoveu-se também, dessa forma, situações desafiadoras que favoreceram a autonomia discente. Para o alcance do segundo objetivo específico, que foi identificar os desafios vivenciados durante a utilização de RED, observou-se que, para os professores, a seleção de um RED para inserção em seu planejamento, por si só, caracterizou-se como um desafio, tendo em vista que eles precisaram relacionar o conteúdo que seria trabalhado às abordagens com o recurso. Nesse ponto, a intencionalidade pedagógica mostrou-se um aspecto importante. Algumas das aulas a envolveram, entretanto, outras não, mostrando que pensar pedagogicamente a utilização de RED ainda é um desafio. Além disso, problemas de conexão dificultaram a utilização dos RED. Para os alunos, as dificuldades envolveram a busca pelos RED e, por vezes, a resolução dos exercícios. Mais uma vez, a mediação docente mostrou-se indispensável para a inserção dos recursos em práticas pedagógicas. Para pesquisas futuras, pensa-se em ampliar o escopo da investigação para outros tipos de RED, como aplicativos educacionais, aliado à formação de professores. Ainda, objetiva- se um estudo mais aprofundado em torno da aprendizagem e a sua facilitação com os RED.

\section{Referências}

Amaral, E. M. H.; Ávila. B.; Zednik, H.; Tarouco, L. (2011) "Laboratório Virtual de Aprendizagem: uma proposta taxonômica". CINTED: UFRGS, v. 9, $\mathrm{n}^{\circ}$ 2, dez.

Arruda, J. S.; Silva, L. M. R. de C. e; Castro Filho, J. A. (2016) "Uso das novas tecnologias na formação dos saberes da docência em professores do ensino fundamental". In: Congresso Regional sobre Tecnologias na Educação - CTRL+e.

Brasil. (1997) "Parâmetros curriculares nacionais: introdução aos parâmetros curriculares nacionais". Brasília: MEC/SEF. 126p. 
Brasil. (2017) “Base Nacional Comum Curricular”. Brasília, DF: MEC, 2017.

Bogdan, R.; Biklen, S. (1991) "Investigação qualitativa em educação: uma introdução à teoria e aos métodos". Portugal: Porto. 336p.

Caiado, R.; Morais, A. G. de. (2013) "Práticas de ensino de Língua Portuguesa com as TDICS".

Educação Temática Digital - ETD, v. 15, no 3, Campinas: São Paulo. p. 578-594.

Castro-Filho, J.; Silva, M. A; Maia, D. L. (2015) "Lições do projeto um computador por aluno: estudos e pesquisas no contexto da escola pública". Fortaleza: EdUECE.

Catto, N. R. (2013) "A relação entre o letramento multimodal e os multiletramentos na literatura contemporânea: alinhamentos e distanciamentos". Fórum Linguístico: Florianópolis, v. 10, $\mathrm{n}^{\mathrm{o}} 2$, p. 157-163.

Fernandes, O. P. (2005) "O computador/internet na formação de pedagogos: um diálogo possível?" REUNIÃO ANUAL DA ANPED, 28.

Hitzschky, R. A.; Brito, M. A. F.; Arruda, J. S.; Melo, M. B. O.; Castro-Filho, J. A. (2016) "Práticas educativas com o uso de dispositivos móveis em aulas de campo: aprendizagem para além dos muros da escola". In: I Congresso Regional sobre Tecnologias na Educação.

Kapp, K. (2012) "The gamification of learning and instruction: Game-based methods and strategies for training and education". San Francisco: Pfeiffer.

Lerner, D. (2002) "A autonomia do leitor: Uma análise crítica". Revista da Educação.

Loureiro, C. B; Lopes, M. C. (2012) "Tecnologias da informação e comunicação: outras formas de condução das condutas". 35 Reunião da ANPEd. Porto de Galinhas: PE.

Medeiros, N. A. A. de; Xavier, C. R. S.; Melo, E. M. de; Andrade, M. A. A. de; Maia, D. L. (2018) "Recursos educativos digitais: uma revisão de literatura em anais de congressos em Informática na Educação". In: III Congresso sobre Tecnologias na Educação (Ctrl+E).

Ramos, J. L.; Teodoro, V. D.; Ferreira, F. M. (2011) "Recursos educativos digitais: reflexões sobre a prática”. Universidade de Évora: Portugal. p. 11-34.

Rojo, R. H. L; Moura, E. (Orgs.) (2012) "Multiletramentos na escola". Parábola Editorial: São Paulo. 264p.

Valente, D. (2014) "A Comunicação e a Educação baseada no uso das Tecnologias Digitais da Informação e da Comunicação". Revista UNIFESO, 1(1), p. 141-166.

Veiga, I. P. A. (2008) “A aventura de formar professores”. In: Veiga, I. P. A.; D’Avila, C. M. Profissão docente: novos sentidos, novas perspectivas. Campinas: Papirus. 